\title{
Simulação de um densímetro nuclear utilizando o código Monte Carlo MCNP-4C
}

\author{
Rodrigo Penna ${ }^{1}$, Clemente José Gusmão Carneiro da Silva ${ }^{2}$, Paulo Maurício Costa Gomes ${ }^{3}$ \\ ${ }^{1}$ Prof. do DCBAS e DCET, UNI-BH; Doutorando em Engenharia Nuclear, UFMG \\ ${ }^{2}$ Prof. da Universidade Estadual de Santa Cruz, UESC, Ilhéus - BA \\ ${ }^{3}$ Prof. do DCBAS e DCET do UNI-BH e da Universidade FUMEC
}

\begin{abstract}
Resumo - Foi Utilizado o código Monte Carlo (MCNP-4C) para simular um densímetro nuclear capaz de medir a densidade da madeira superficialmente. Utilizou-se uma fonte de Amerício-241, de baixa energia $(E=60 \mathrm{Kev})$ o que permite uma maior segurança na operação. Os resultados mostraram que a densidade da madeira pode ser medida partir da radiação espalhada devido ao Efeito Compton. A técnica representa um avanço em relação à metodologia atual.

palavras-chave - madeira, densidade, radiação, Espalhamento Comton, monp
\end{abstract}

Abstract - Viability of building a nuclear wood densimeter based on low energy photons Compton scattering was done using Monte Carlo code (MCNP- 4C). It is simulated a collimated $60 \mathrm{keV}$ beam of gamma rays emitted by 241Am source reaching wood blocks. Backscattered radiation by these blocks was calculated. Photons scattered were correlated with blocks of different wood densities. Results showed a linear relationship on wood density and scattered photons, therefore the viability of this wood densimeter.

keywords - radiation, wood, Compton Scatterign, density, monp

\section{INTRODUÇÃO}

As indústrias brasileiras que usam apenas o eucalipto como matéria-prima para a produção de papel, celulose e outros derivados da madeira representam 4\% do nosso PIB, 8\% das exportações e geram cerca de 150 mil empregos [1]. O setor florestal é um dos setores da economia brasileira que apresentou os maiores efeitos multiplicadores para os indicadores socioeconômicos, sendo superiores aos de outros, como o da indústria automobilística, de equipamentos elétricos e eletrônicos, de máquinas e equipamentos e de produtos químicos e petróleo [2]. A madeira é matéria prima para a indústria moveleira, de papel e celulose e siderúrgica, na forma de carvão, dentre outras. Seja legalizada ou proveniente de desmatamento ilegal, infelizmente, como temos visto com freqüência, ela movimentou em 2002 US\$21 bilhões de dólares no PIB brasileiro [3]. Com investimentos cada vez maiores em pesquisa e aprimoramento genético, um dos parâmetros mais importantes no caso da madeira é justamente sua densidade [4]. Ela determina uma série de propriedades e de características da madeira, permitindo melhorar e prever suas futuras aplicações [5].

A densidade é uma grandeza conhecida e sua medida costuma vir da relação direta entre a massa e o volume. Se pensarmos em algumas dezenas de milhares de árvores plantadas em uma única fazenda, a simples colheita das amostras e medida de suas densidades envolve relativamente bastante mão de obra, e qualificada, e instalações adequadas, laboratório próprio, no caso.

Existem outros métodos, interessantes, inclusive, para medida da densidade da madeira, especificamente. $\mathrm{O}$ chamado método gravimétrico, por exemplo, consiste em deixar cair, a partir do repouso, um peso com ponta afiada sobre a madeira. A altura de queda é previamente estabelecida. Dependendo do quanto a ponta deste tipo de lança penetra na madeira, uma calibração prévia fornece uma estimativa da densidade. Porém, este não é um método muito preciso.

O Departamento de Engenharia Nuclear da UFMG tem despendido esforços no desenvolvimento de técnicas para medida de densidade e umidade de materiais porosos [6]. Tais técnicas, baseadas no Espalhamento Compton da radiação, mostraram-se eficientes tanto para solos [7], outro material cuja densidade é de grande interesse, quanto também para a madeira [8]. Pesquisas para sua aplicação em novos materiais estão em andamento. 
O espalhamento Compton, também chamado de Efeito Compton, pode ser interpretado como a colisão de um fóton de radiação com um elétron. Considerando a energia do fóton, a energia de ligação do elétron ao átomo é desprezível e ele se comporta como livre. Aplicando as equações de conservação do momentum linear e da energia - relativísticas - a colisão ocorre provocando o espalhamento do elétron em um ângulo e do fóton, normalmente de energia menor que o incidente - parcialmente elástica - em outro. Grosso modo, semelhante à colisão de duas bolas de sinuca.

Dando prosseguimento a esta linha de pesquisa, agora se trabalha no intuito de construir um densímetro nuclear compacto. Tal aparelho, de tamanho próximo de um palmtop ou smartphone, conterá uma fonte radioativa de baixa energia e baixa intensidade e que, portanto, poderia ser transportada com segurança de acordo com as normas vigentes. A fonte de energia escolhida foi a de Amerício241, de meia-vida 458 anos e energia na faixa de $60 \mathrm{keV}$, o que requer pequenas espessuras de chumbo para uma eficiente blindagem quando comparadas com outros radionuclídeos de maior energia, tais como o cobalto-60 ou césio-137.

Trabalhos anteriores realizados por Penna [9] utilizaram, com sucesso, uma sonda nuclear para medidas de densidade da madeira. A simulação de um densímetro, utilizando o código Monte Carlo - MCNP-4C, permite o estudo de uma montagem de pequenas dimensões e de grande eficiência, com geometria otimizada, de forma que o aparelho que vier a ser montado como protótipo opere da maneira a mais precisa possível.

\section{MATERIAIS E MÉTODOS}

Para a simulação do densímetro, foi utilizada a versão 4C do código Monte Carlo, disponibilizada pela AIEA - Agência Internacional de Energia Atômica.

Este programa de computador, já consagrado para utilização em Engenharia Nuclear, permite simular a interação da radiação com a matéria. É chamado de Monte Carlo em referência ao mundialmente famoso cassino que lá se encontra. Ele trabalha calculando a probabilidade - e, por isto, a referência ao cassino - de que um fóton, ou nêutron, por exemplo, interaja com a matéria dependendo de suas características: constituição atômica e densidade. E entre os vários tipos de interação possíveis, fornece a probabilidade de ocorrência de cada uma. A versão 4C não possui uma interface amigável e opera no sistema DOS. Porém, e o que é relevante, permite cálculos probabilísticos extremamente complexos, como simulações de reatores nucleares.

A primeira simulação foi para constatar a viabilidade da medida da densidade fazendo incidir sobre a madeira radiação gama de $60 \mathrm{keV}$ proveniente de uma fonte de Amerício-241 colocada diretamente sobre a amostra. Para evitar o espalhamento da radiação e seguindo as orientações de radioproteção, a fonte foi abraçada por blindagem de chumbo adequada. Um único orifício permitia a saída da radiação sobre a madeira.

Para a detecção da radiação, foi simulado um cintilador plástico. Ao ser atingido por radiação, ele emite fótons de luz visível que podem ser contados por aparato eletrônico adequado. Assim, a medida da luz fornece uma medida da quantidade de radiação que retornou até o cristal cintilador.

O princípio básico do densímetro foi simulado da seguinte forma:

1 - radiação é emitida pela fonte e penetra na madeira;

2 - fótons sofrem Espalhamento Compton e são desviados em várias direções, sendo uma parte, inclusive, absorvida pela própria madeira, dependendo das dimensões da amostra;

3 - O Espalhamento Compton depende diretamente da densidade do material. Quanto maior a densidade, maior a quantidade de radiação espalhada;

4 - Uma parte da radiação espalhada na madeira consegue voltar a atingir o cintilador, 
que emite luz. Quanto mais densa a madeira, mais radiação espalhada atinge o cintilador.

A figura 1 é uma representação esquemática do densímetro e de como ele foi programado utilizando o código MNCP-4C.

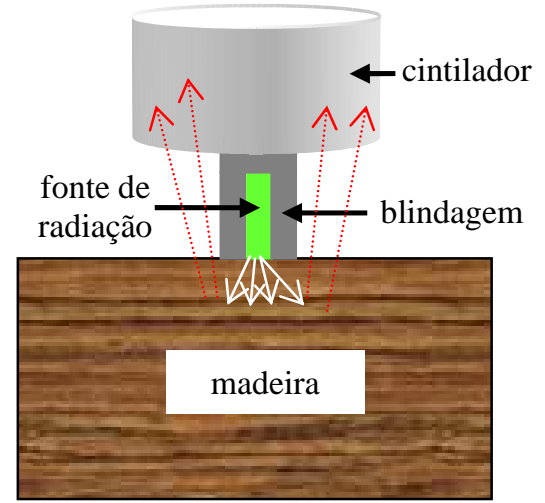

Figura 1. Esquema para a medida da densidade da madeira superficialmente.

A madeira é composta basicamente de celulose. Formada, portanto, por átomos leves, essencialmente de Carbono, Hidrogênio e Oxigênio. Os materiais de todos os componentes do densímetro são escritos na programação a partir de uma biblioteca interna do próprio código.

Uma segunda simulação foi feita com o cintilador embutido também na blindagem, esta mais robusta. Sempre mantendo uma camada de chumbo entre a fonte e o cristal, para evitar que radiação direta, proveniente da fonte, atinja o cintilador, o que inviabilizaria o funcionamento do aparelho. O esquema desta outra simulação se encontra na figura 2.

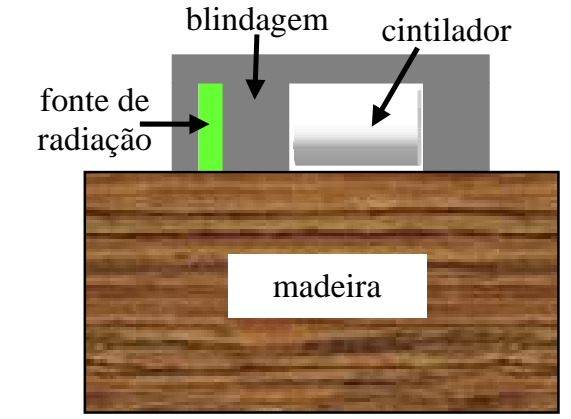

Figura 2. Simulação com a fonte e o cintilador dentro da blindagem.
Por fim, foi feita uma terceira simulação, desta vez na mesma geometria anterior, com uma fonte de radiação alternativa: Césio-137. A diferença foi a espessura da blindagem de chumbo, visto que a energia da radiação emitida por esta fonte é de $662 \mathrm{keV}$. Portanto, cerca de 11 vezes maior que a radiação gama do Amerício.

Em todos os casos, a densidade da madeira foi programada em uma faixa bem abrangente, de 0,4 até $1,4 \mathrm{~g} / \mathrm{cm}^{3}$. Como o objetivo é apenas a medida desta densidade, foi tomada como parâmetro apenas a contagem total da radiação, já que não seria necessário verificar-se o espectro da radiação espalhada. Providência que será tomada quando da montagem do protótipo experimental.

\section{RESULTADOS E DISCUSSÃO}

A figura 3 mostra a regressão linear dos resultados obtidos com a primeira simulação, fonte de Amerício dentro da blindagem e cintilador externo. Observamos uma resposta bastante linear entre o aumento no fluxo de fótons no cintilador e o aumento da densidade da madeira. O coeficiente de correlação $\mathrm{R}^{2}$ foi de 0,99. Este resultado mostra a possibilidade da montagem de um aparato capaz de medir a densidade da madeira fazendo a radiação incidir sobre ela e detectando os fótons espalhados, por exemplo, com um cintilador plástico. A resposta cobre toda a faixa de densidade da madeira, podendo a princípio ser utilizado para a medida da densidade de qualquer espécie. O cintilador poderia ser calibrado pela equação da reta obtida experimentalmente com várias amostras de madeira de densidades previamente conhecidas.

\section{Gráfico Densidade x Fluxo de fótons}

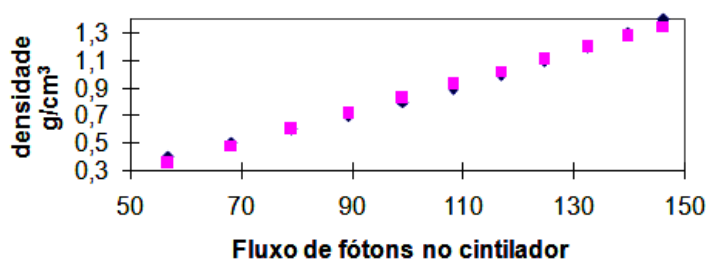

Figura 3. Regressão linear da simulação com o cintilador externo à blindagem. 
Alterando-se a montagem para embutir o cintilador dentro da blindagem, também se obteve uma resposta linear Fig.4. Observa-se que o fluxo de fótons no cintilador diminui, como era esperado. Isto porque, protegido pelo chumbo, a área útil a ser atingida pelos fótons foi reduzida. Porém, isto não comprometeria uma eventual medida da densidade. No máximo, para aprimoramento da precisão da medida, a fonte deveria ser exposta durante mais tempo e compensaria tal efeito. Pois o coeficiente de correlação foi da mesma ordem que o anterior, 0,98 .

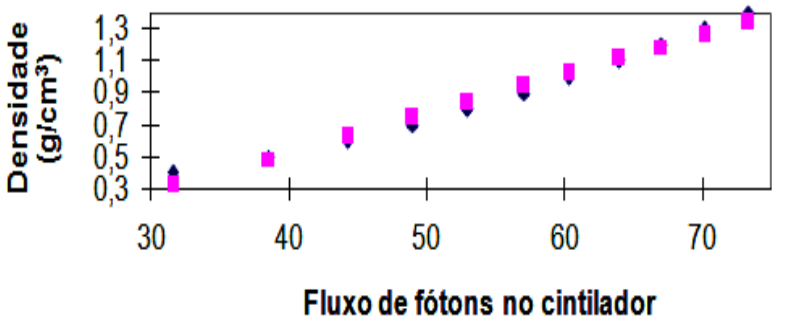

Figura 4. Regressão linear da simulação com o cintilador embutido na blindagem.

Finalmente, a simulação com o Césio-137 apresentou linearidade, apesar do aumento na energia da radiação. O coeficiente de correlação foi de 0,99. Apesar disto, as contagens diminuíram em relação ao Amerício. Provavelmente porque a espessura da madeira simulada, $8 \mathrm{~cm}$ de raio, permitiu a passagem da radiação gama muito energética. $\mathrm{E}$, portanto, o espalhamento na direção do cintilador foi menor. O que, aliás, é visto pela fórmula de Klein-Nishina: quanto maior a energia da radiação incidente menor também será o ângulo de espalhamento [10]. Além do que, foi preciso simular uma blindagem mais espessa, justamente devido à maior energia. E, neste caso, como o objetivo do aparelho é ser compacto, seria mais adequada a utilização do Amerício-241.

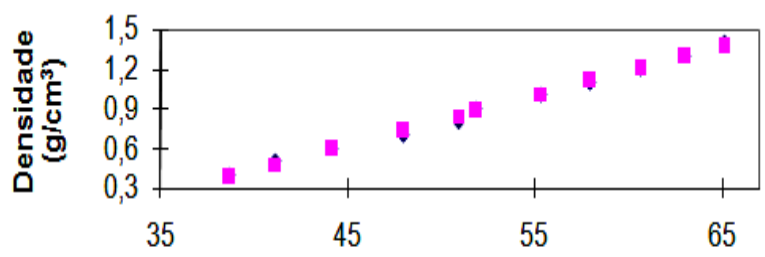

Fluxo de fótons no cintilador

Figura 5. Regressão linear da simulação com a fonte de Césio-137.

Partindo destas primeiras simulações, seria preciso estudar a geometria mais adequada para otimizar o funcionamento do densímetro. Entre outros parâmetros que podem influir em seu desempenho estão a posição da fonte, sua angulação em relação à madeira e a posição e dimensão do cintilador, bem como as dimensões da amostra de madeira para verificar os limites de detecção e precisão. Tudo a ser verificado experimentalmente quando o protótipo estiver montado e funcionando.

\section{CONCLUSÕES}

Pelos resultados apresentados em todas as simulações, verifica-se a viabilidade da montagem do densímetro. Geometrias diferentes apresentam resultados satisfatórios. O Amerício-241 mostrou-se eficiente na medida da densidade da madeira. Embora seja possível a medida da densidade também com Césio, a própria radioproteção recomenda a utilização da menor energia possível da radiação. A continuação das pesquisas permitirá a otimização do sistema, quanto à geometria a ser utilizada para obtenção de maior eficiência e melhor precisão. O programa Monte Carlo mostrou-se, mais uma vez, uma ferramenta versátil para a avaliação preliminar da montagem de sondas nucleares.

\section{AGRADECIMENTOS}

Os autores fazem questão de agradecer ao CNPQ e à Capes o apoio e o financiamento aos projetos de pesquisa, tão essenciais. $\mathrm{E}$ ao 
UNI-BH a mais uma oportunidade de divulgação com qualidade das pesquisas desenvolvidas no estado de Minas Gerais.

\section{REFERÊNCIAS}

[1] MINISTÉRIO DA CIÊNCIA E TECNOLOGIA. Eucaliptos mais resistentes, indústrias menos poluentes. Disponível em: http://ftp.mct.gov.br/especial/genolyptus5.ht m. Acesso em: 04 de out. 2008.

[2] VALVERDE, Sebastião Renato et al . Efeitos multiplicadores da economia florestal brasileira. Rev. Árvore, Viçosa, v. 27, n. 3, 2003 . Disponível em: $<$ http://www.scielo.br/scielo.php?script=sci arttext\&pid=S0. $100-$

67622003000300003\&lng $=\& n r m=i s o>$. Acesso em: 10 2008. doi: 10.1590/S010067622003000300003. 2003.

[3] R. Noce, M.L. Silva, T.S. Soares e R.M.M.A. Carvalho. Análise de risco e retorno do setor florestal: produtos da madeira. Árvore, Viçosa, v.29, n.1, p.77-84, 2005.

[4] Zobel, B. J. and Talbert , J. Applied Forest Tree Improvement. New York, John Wiley \& Sons, 1984.
[5] Bowyer, J. L., Smith, R. L. The Nature of Wood and Wood Products. CD-ROM, University of Minnesota, Forest Products Management Development Institute, St. Paul, 1998.

[6] Silva, M. R. S. Desenvolvimento de um densímetro nuclear por Difusão Compton utilizando um guia líquido de luz. 2004. 54p. Dissertação (Mestrado em Ciências e Técnicas Nucleares) - Departamento de Engenharia Nuclear, Universidade Federal de Minas Gerais, Belo Horizonte. 2004.

[7] Aguiar, M. J. Desenvolvimento de uma sonda nuclear para medida de umidade de solos por Espalhamento Compton. 2006. 45p. Dissertação (Mestrado em Ciências e Técnicas Nucleares) - Departamento de Engenharia Nuclear, Universidade Federal de Minas Gerais, Belo Horizonte. 2006.

[8] [9] Penna, R. Sonda nuclear para medida da densidade da madeira por Espalhamento Compton. 2006. 69p. Dissertação (Mestrado em Ciências e Técnicas Nucleares) Departamento de Engenharia Nuclear, Universidade Federal de Minas Gerais, Belo Horizonte. 2006.

[10] Knoll, G. F. Radiation detection and measurement. New York: John Wiley \& Sons, 1989. p. 52-54. 